\begin{tabular}{|c|ccc|c|}
\hline & PORT SAID ENGINEERING RESEARCH JOURNAL \\
\hline
\end{tabular}

\title{
Effects of Shaft Misalignment on the Stresses Distribution on teeth of Spur Gears
}

\begin{abstract}
Shaft misalignment is a common problem in most rotating machines. It leads to generate vibration and extra dynamic loading on power transmitting elements, such as gears. Furthermore, it leads to irregular distribution of applied loading on the faces of teeth of mating gears by being concentrated on one side of tooth face. The work presented in this paper focuses on studying the effects of shaft misalignment on stresses distribution on transmitting gear tooth. This is important for gear designers and for those who work in gear maintenance, especially to avoid fracture that is expected to initiate and propagate at the locations of stress concentration. A Finite Element (FE) package (ANSYS) was utilised to conduct this study, where, . 3D ele ments of two mating gears were modeled aiming to examine the resultant stresses under modified misalign ment conditions.. In order to minimize the computational time, only one tooth of each gear was considered for simulation. The in fluence of the inclination angle of the shafts that the gears were attached was assessed. in particular, . Different FE analyses were carried out where the inclination angle varied from $0.0^{\circ}$ to $2^{\circ}$ in $0.5^{\circ}$ step. The obtained results reveal that stresses concentration increases with the increase of the angle of inclination. . As a result, the possibility of the fracture of the gear increases in the root with increasing the misalign ment angle.
\end{abstract}

Kandil, A. ${ }^{1}$, Abd El-Gwad, E. ${ }^{2}$ and Yassen, $M .^{3}$

Keywords: Spur gear, gear tooth, misalign ment angle, finite ele ment analysis, bending stress, contact stress

\section{NOMENCLATURE}

$\begin{array}{ll}b & \text { Tooth Face Width in mm } \\ C_{p} & \text { Elastic Factor in } \mathrm{MPa}^{0.5} \\ d_{p} & \text { Pinion Diameter in } \mathrm{mm} \\ F_{t} & \text { Tangential Force in } \mathrm{N} \\ I & \text { Geometry Factor } \\ J & \text { Geometry Factor } \\ k_{a} & \text { Applied Load Factor } \\ k_{m} & \text { Load Distribution Factor } \\ k_{v} & \text { Dynamic Factor } \\ m & \text { Module in mm } \\ \sigma_{b} & \text { Bending Stress in } \mathrm{MPa} \\ \sigma_{c} & \text { Contact Stress in } \mathrm{MPa} \\ \end{array}$

\section{INTRODUCTION}

When one investigates actual gears in service, the conditions of failure due to contact and bending stresses are the most important features to be considered [1]. Due to bending stress, fracture of gear tooth is likely to occur at tooth root area where tension stresses concentrate; hence cracks may initiate and propagate at root area when maximum generated stress at this area exceeds the failure

\footnotetext{
${ }^{1}$ Professor, Production Engineering and Mechanical Design Department, Faculty of Engineering, Port Said University, Port Said, Egypt,E-mail: Anwarkandil@hotmail.com

${ }^{2}$ Professor, Production Engineering and Mechanical Design Department, Faculty of Engineering, Port Said University, Port Said,, Egypt, E-mail: Ebtisam1953@yahoo.com

${ }^{3}$ Production Engineering and Mechanical Design Depantment, Faculty of Engineering, Port Said University, Port Said, Egypt, E-mail: Yassen880@yahoo.com
}

strength. Moreover, pitting may occur due to stress concentration at contact area. Bending and contact stresses generated in gear teeth depend on many variables such as transmitted load, running speed, tooth geometry, contact ratio and other design considerations.

This work specifically investigates the effects of the shaft misalignment on bending and contact stresses acting on in-operation gear teeth.

In 2004, Wei, Z. [2] studied the stress analysis of meshed gear tooth under bending and contact stresses using finite element method. The values and distribution of bending and contact stress which were obtained from that study agreed well with those obtained using the American Gear Manufacture Association (AGMA) equations. In 2006, Decaires, J.K. [3] presented a statistical tooth engagement model (STEM) which allows designers to estimate tooth engagement and resulting stress based on a statistical representation of the tooth errors. In 2008, Rixin, $X$. [4] has built a three dimensional finite element model of the spur gear system to investigate stress distribution and analyse the advantage of quenching process. A fullscale deformable body model and a simplified discrete model were both shown to be accurate through extensive comparisons to the theoretical database generated in that study. In 2009, Stoker, K., C. [5] has provided engineers with a tool to predict where and by how much the stresses of spur gears will increase when non ideal conditions are present for both two dimensional and three dimensional FE analyses. The research has shown that with an increase in the axial separation wear depths will increase and the wear profile will be modified. In 2010, Patel, S. [6] 
worked on developing an analytical approach and modelling procedure to evaluate stress distribution under velocity and moment that would provide a useful tool to improve spur gear design with high efficiency and low cost. The purpose of this work is to analyse and validate the stress distribution in spur and helical gears using a contemporary commercial FE method program ANSYS coupled with the Pro/E solid modeller. In 2012, Gupta, et al., [7] studied contact stress analysis of spur gear using finite element analysis and verified the results with (A GMA) equation. Also, in 2012, Panchal, J., K. [8] studied bending and surface pressure of external teethed involute spur gear by developing a program in Mathcad software. The program was designed to calculate surface and bending stress data by input such as pitch, face width, pressure angle, horse power, and load.

Therefore, it is obvious that the relationship between the shafts misalignment and stress distribution has not fully recovered. This paper aims at studying the effects of misalignment of shaft axes on stresses distribution on the spur gear tooth using finite ele ment method.

\section{BENDING STRESS ANALYSIS}

\subsection{Bending stre ss model}

Modern gear design procedures take into account several modification factors that influence gear tooth bending stress. AGMA has presented an equation to calculate bending stress on gear tooth [9-11] as follows:

$$
\sigma_{b}=\frac{F_{t} \times K_{a} \times K_{m}}{b \times m \times J \times K_{v}}
$$

This AGMA equation will be used to verify that the presented bending stress which is modeled by ANSYS is accurate and it can be used to predict the behavior of bending stress on the tooth under non-ideal conditions.

To satisfy this case, an involute toothed gear has been built in Solidworks program, using the data given in Table 1.

Table 1: Data used for gear drawing

\begin{tabular}{|l|c|}
\hline \multicolumn{1}{|c|}{ Gear Parameter } & Value \\
\hline Number of teeth $(Z)$ & 25 teeth \\
\hline Module $(m)$ & $4 \mathrm{~mm}$ \\
\hline Pressure Angle $(\phi)$ & $20^{\circ}$ \\
\hline Face Width $(b)$ & $15 \mathrm{~mm}$ \\
\hline
\end{tabular}

AISI 1020 steel is used for gear material with modulus of elasticity $(E)$ of $200 \times 10^{3} \mathrm{MPa}$ and Poisson's ratio (v) of 0.3 [12].

In order to minimize the computation the symmetry of the gear teeth was utilised. In particular, a single gear tooth has been constructed by Solidwork program in the present work to simulate spur gear tooth, as shown in Fig. 1.

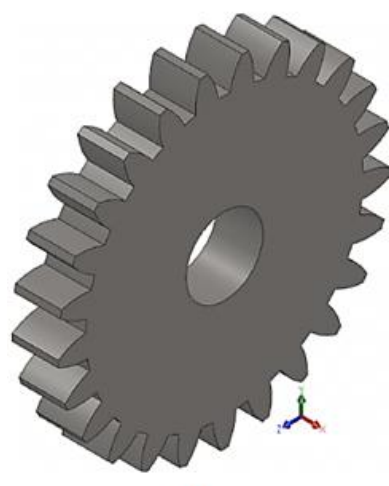

(a)

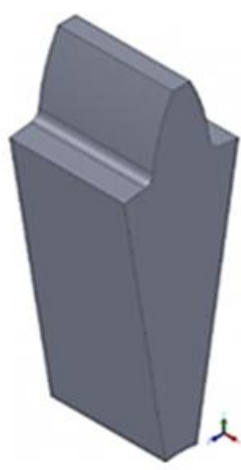

(b)
Fig. 1: (a) Spur gear model (b) S ingle tooth model.

The single tooth model was exported from Solidworks program to ANSYS program to construct the bending stress model. The model was meshed using the solid tetrahedral elements with $1 \mathrm{~mm}$ as the element average size. Fine meshe was used at tooth root fillet area as shown in Fig. 2.

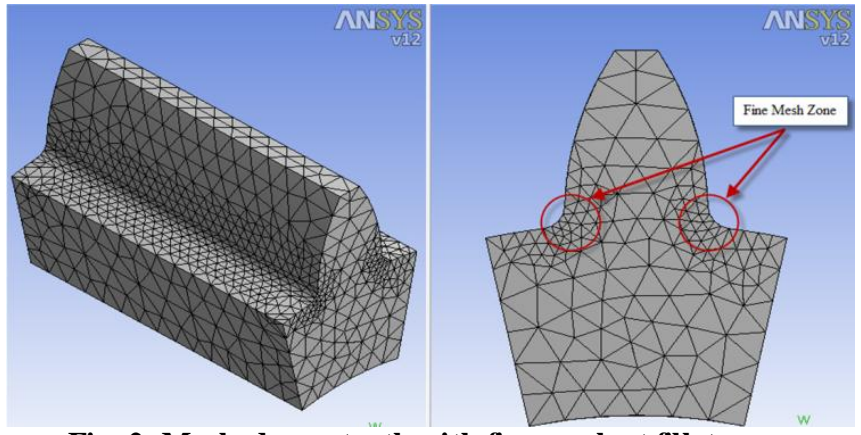

Fig. 2: Meshed gear tooth with fine mesh at fillet areas

Bending model was fully fixed in $X, Y$ and $Z$ directions by applying zero translational and rotational boundary condition in those directions. The applied load to the tooth model was a normal force of $1,064 \mathrm{kN}$ at the top surface of the tooth, see Fig. 3.
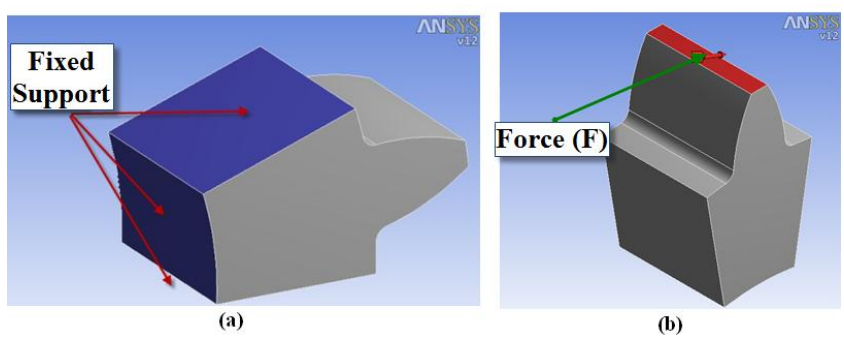

Fig. 3: (a) Boundary conditions, (b) Applied load on the tooth model.

Accordingly, the bending stress distribution over the tooth has been calculated and illustrated in Fig. 4. 


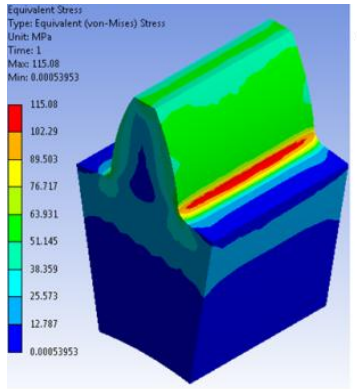

(a)

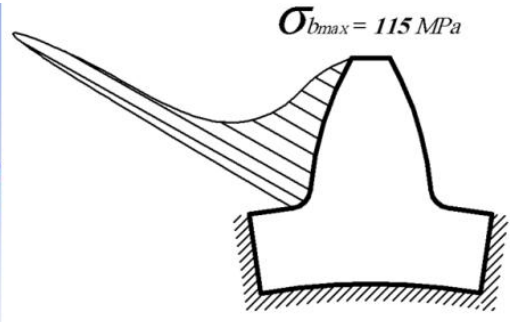

(b)
Fig. 4: Bending stress distribution (a) over the whole tooth (b) on one tension side of the tooth

Using AGMA equation, Eqn. 1, and the data listed in

Table 2, the maximum bending stress, $\sigma_{b}$, was found to be $109 \mathrm{MPa}$.

Table 2: Average value of AGMA modifications factors [9]

\begin{tabular}{|l|c|}
\hline \multicolumn{1}{|c|}{ Experimental Factors } & Value \\
\hline Application factor $\left(K_{a}\right)$ & 1.25 \\
\hline Load distribution factor $\left(K_{m}\right)$ & 1.3 \\
\hline Dynamic load factor $\left(K_{v}\right)$ & 0.7 \\
\hline Geometry factor $(J)$ & 0.355 \\
\hline
\end{tabular}

$$
\sigma_{b}=\frac{1000 \times 1.25 \times 1.3}{15 \times 4 \times 0.335 \times 0.7}=108.99 \mathrm{MPa}
$$

The maximum bending stress obtained from ANSYS was about $115 \mathrm{MPa}$,as shown in Fig. 4-a. It is clear that both the numerical maximum bending stress agrees well with that obtained sing AGMA equation.

\subsection{Conditions of misalignment}

Shafts could be misaligned in vertical plane, in horizontal plane or in both vertical and horizontal planes. Fig. 5 shows three cases of shafts misalign ments compared to ideal case, i.e. without misalign ment. The misalign ment cases are: case (a) presents two parallel shafts without misalignment; case (b) shafts are misaligned in the vertical plane; case (c) shafts are misaligned in the horizontal plane and case (d) shafts are misaligned in both the vertical and horizontal planes.

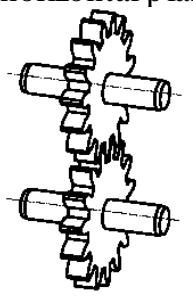

(a)

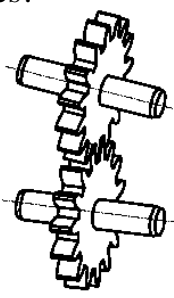

(b)

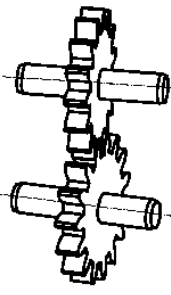

(c)

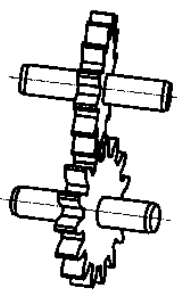

(d)
Fig. 5: Misalignment conditions (a)without misalignment (b) misalignment in vertical plane (c) misalignment in horizontal plane (d) misalignment in both vertical and horizontal planes [13]

\subsection{Effects of misalignment in bending model}

After verifying that the bending stress model without misalignment is satisfactorily accurate, it has been used to predict the bending stress acting on the gear tooth under the effect of misalign ment in varies directions.

\subsubsection{Gears misalign in the vertical plane}

The constructed bending model has been used, and some developments are introduced to it to agree with the requirements of the study. When shafts are misaligned in the vertical plane, the new bending model is developed, according to the applied normal load acting on an inclined line along the gear tooth width as seen inFig. 6.

The misalignment angle $\theta_{l}$ in the vertical plane changed from $0^{\circ}$ to $2^{\circ}$. Three different modules $(\mathrm{m}=2,3,4 \mathrm{~mm})$ were used. The applied boundary conditions and load were the same as those used in the bending model without mis alignment.
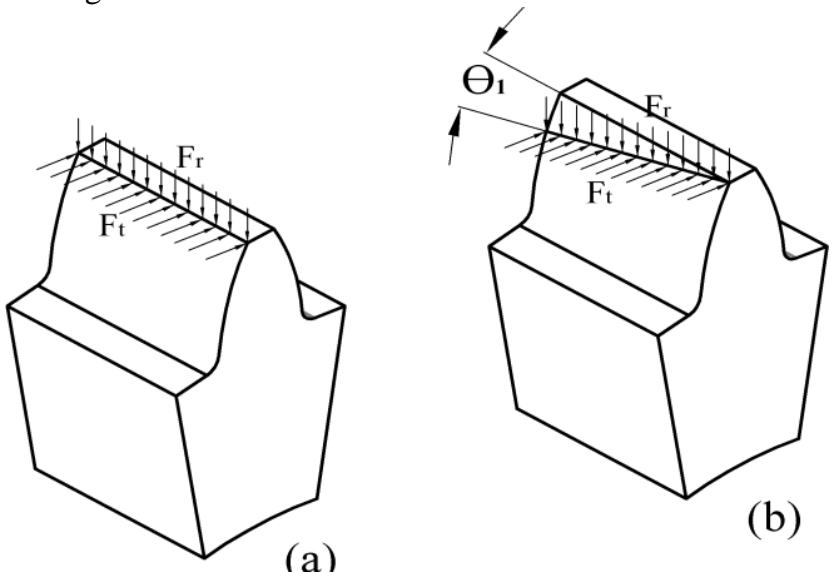

(b)

Fig. 6: Effect of misalignment in the vertical plane (a) Without misalignment, (b) With misalignment

Figures 7 and 8 illustrate the effect of the misalignment angle $\theta_{1}$ in the vertical plane on the tooth bending stress $\sigma_{b}$ for different investigated modules. It can be seen that as the increasing of the misalignment angle $\theta_{1}$, in the vertical plane, increases the maximum bending stress increases. Fig. 7 shows that, for the same misalignment angle, the maximum bending stress decreases with increasing the module of the gear; as the module increase the tooth size increase and its ability to withstand stresses increase. Furthermore, it can be seen that the rate of increasing the bending stress for $m=2$ is higher than that for $m=3$ and $m=4 \mathrm{~mm}$.

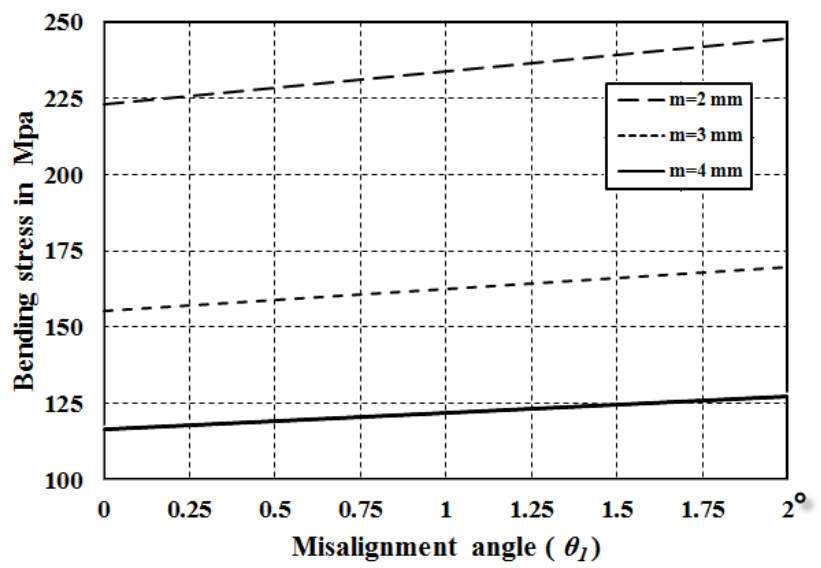

Fig. 7: Bending stress vs. misalignment angle in the vertical plane for different modules 


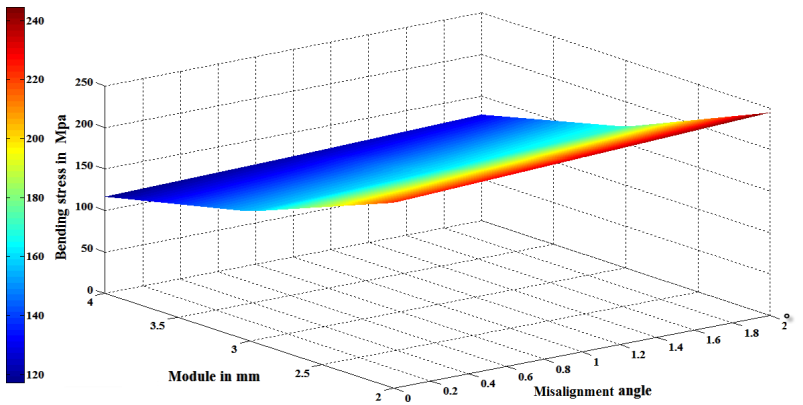

Fig. 8: Bending stress vs. misalignment angle in the vertical plane for different modules in 3D-plot

Bending stress distribution over the gear tooth model of $\mathrm{m}=4 \mathrm{~mm}$ is given in Fig. 9, without misalignment and with misalignment of $2^{0}$ in the vertical plane.

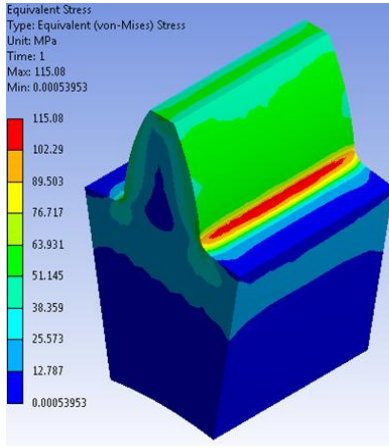

(a)

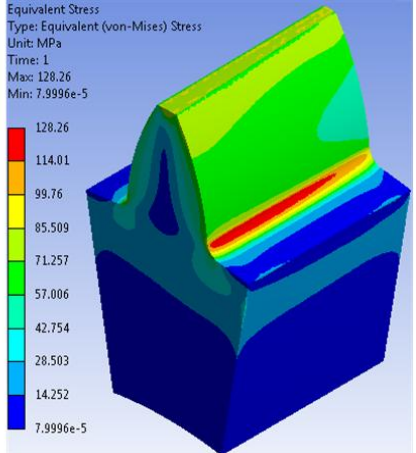

(b)
Fig. 9: Bending stress distribution over the tooth of $4 \mathrm{~mm}$ module (a) without misalignment, (b) with $2^{o}$ misalignment in vertical plane

\subsubsection{Gears misalign in the horizontal plane}

When shafts are misaligned in the horizontal plane, the new bending model is developed, according to the new direction of the normal load. The applied load becomes non-uniformly due to the horizontal misalignment as shown in Fig. 10.
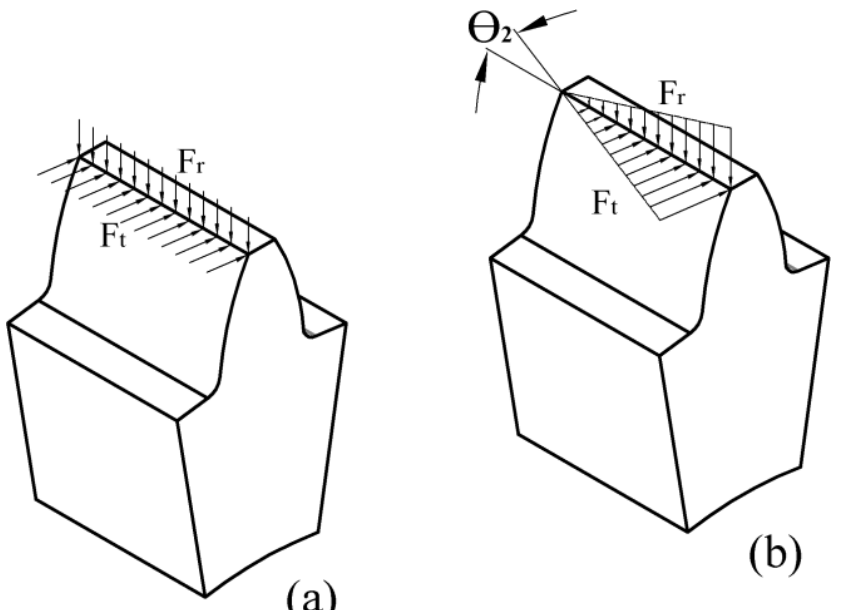

(a)

(b)

Fig. 10: Effect of misalignment in the horizontal plane (a) without misalignment, (b) with misalignment
The misalignment angle $\theta_{2}$ in the horizontal plane ranges from $0^{\circ}$ to $2^{\circ}$. Also, three different modules $(\mathrm{m}=2,3,4$ $\mathrm{mm}$ ) were used. The applied boundary conditions and load were the same as those used in the bending model without misalign ment. However, the applied load was not uniformly distributed along the gear tooth width, see Fig. 10(b).

Figures 11 and 12 illustrate the effect of the misalignment angle, $\theta_{2}$, in the horizontal plane on the tooth bending stress $\sigma_{b}$ for different investigated modules.Similar to the results obtained from misalignment in vertical plane, Fig. 11 shows that as the misalignment angle $\theta_{2}$,in the horizontal plane increases the maximum bending stress increases. Fig. 11 shows, also, that for the same misalignment angle, the maximum bending stress decreases with increasing the module of the gear; as the module increase the tooth size increase and its ability to withstand stresses increase. Furthermore, it can be seen that the rate of increasing the bending stress for $m=2$ is higher than that for $\mathrm{m}=3$ and $\mathrm{m}=4 \mathrm{~mm}$.

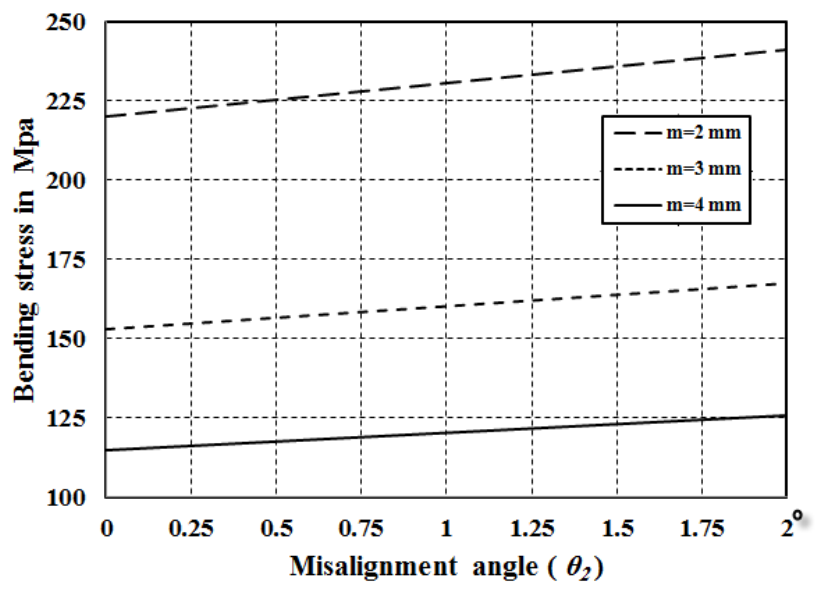

Fig. 11: Bending stress vs. misalignment angle in the horizontal plane for different modules

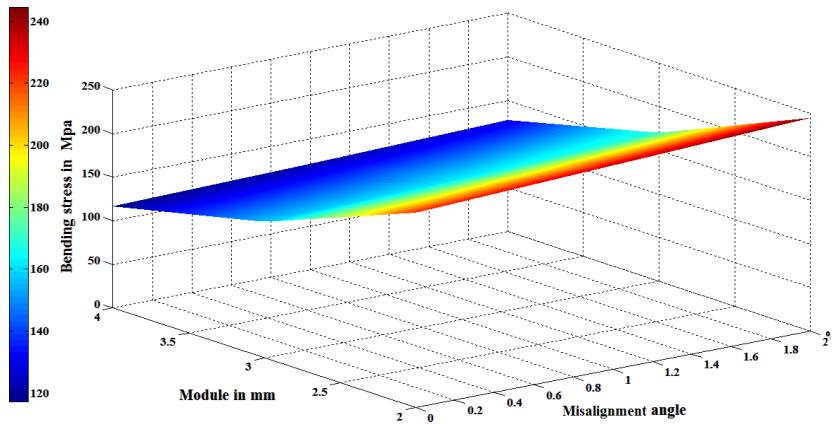

Fig. 12: Bending stress vs. misalignment angle in the horizontal plane for different modules in 3D-plot

Fig. 13 shows the distribution of bending stress over the gear tooth of $4 \mathrm{~mm}$ module with and without misalign ment. 


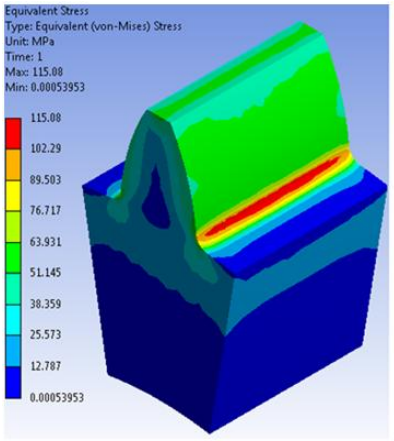

(a)

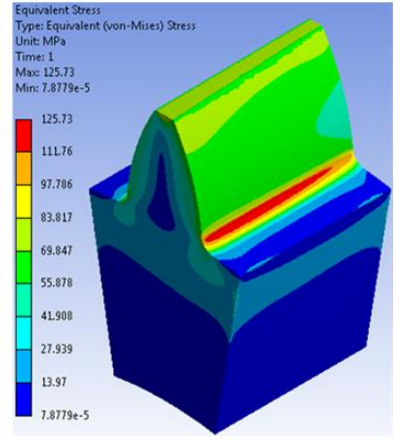

(b)
Fig. 13: (a) Bending stress distribution over the tooth of $\mathbf{m}=$ $4 \mathrm{~mm}$ (a) without misalignment, (b) with $2^{o}$ misalignment in horizontal plane

\subsubsection{Gears misalign in both vertical and horizontal planes.}

When shafts are misaligned in both vertical and horizontal planes, a new bending model is developed to simulate the non-uniformly distributed load on an inclined line along the gear tooth width as shown in Fig. 14.
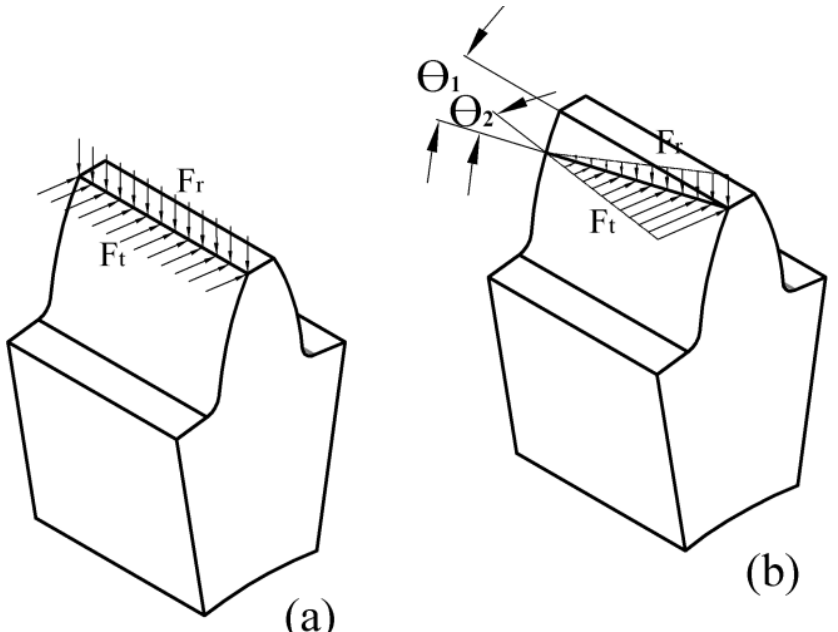

(b)

(a)

Fig. 14: Effect of misalignment in both the vertical and horizontal planes (a) without misalignment, (b) with misalignment

The study was carried out assuming equal misalignment angles: $\theta_{1}$ in the vertical plane and $\theta_{2}$ in the horizontal plane, which are changed equally from $0^{\circ}$ to $2^{\circ}$ in each case. Three different modules $(\mathrm{m}=2,3,4 \mathrm{~mm})$ for the same gear geometry were used. Same boundary conditions and same applied load were used as those used in the bending model.

Figures 15 and 16 illustrate the effect of the misalignment angles $\theta_{1}$ and $\theta_{2}$ on the tooth bending stress $\sigma_{b}$ for different investigated modules. It can be seen that the increasing misalignment angles $\theta_{1}$ and $\theta_{2}$ results in increasing the bending stress for all modules. Also, it can be seen that module of $2 \mathrm{~mm}$ has the maximum bending stress.

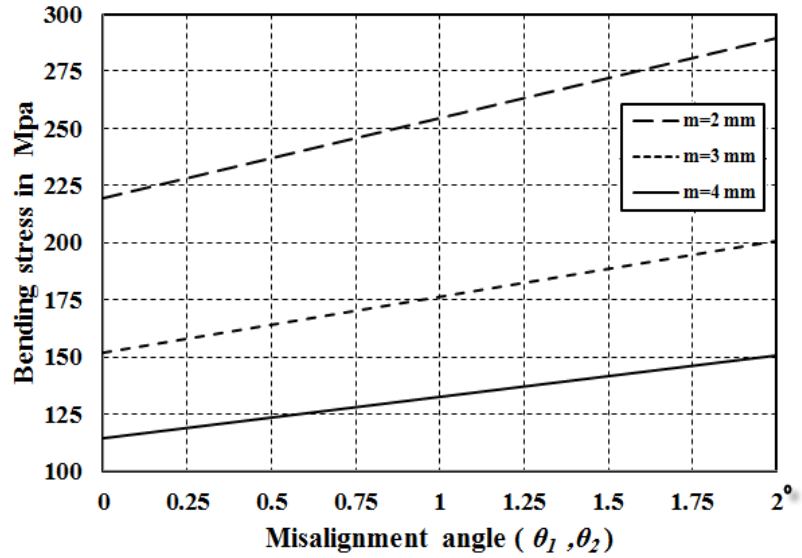

Fig. 15: Bending stress vs. misalignment angle in the vertical and horizontal planes for different modules

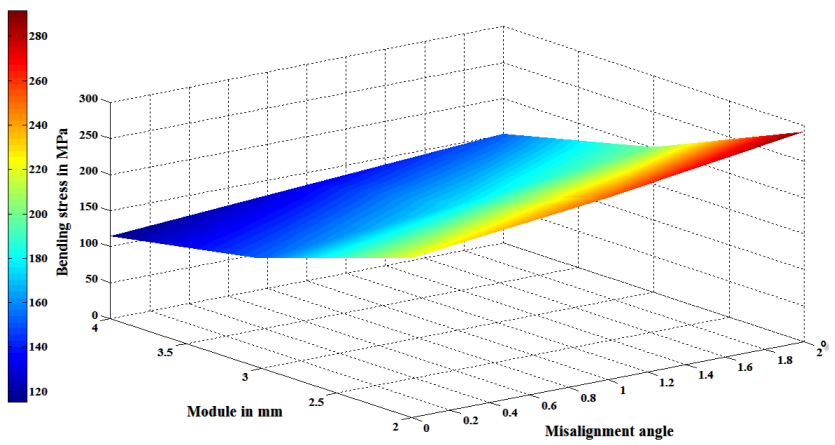

Fig. 16: Bending stress vs. misalignment angle in the vertical and horizontal planes for different modules in 3D-plot

Fig. 17 shows the distribution of bending stress over the gear tooth of $4 \mathrm{~mm}$ module with and without misalign ment.

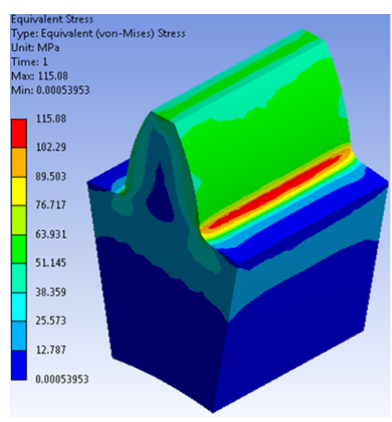

(a)

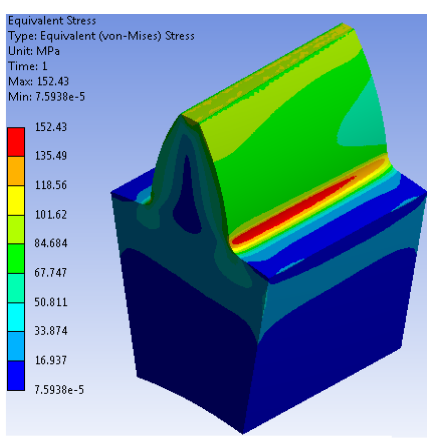

(b)
Fig. 17: (a) Aligned gear axes, (b) Misaligned gear axes in both vertical and horizontal planes

It can be observed that the behavior of the bending stress acting on gear tooth when the shaft are misalinged in vertical plane is similar to that when the shafts are misaligned in horizontal plane. In other words, the value of bending stress acting on the gear tooth is quite the same as its value for the same misalign ment angle in the horizontal plane. When misalignment angle is located in both vertical and horizontal planes, the value of bending stress acting on the gear tooth is higher. 


\section{CONTACT STRESS ANALYSIS}

\subsection{Contact stre ss model}

AGMA has presented an equation to calculate contact stress on gear tooth [9-11] as follows:

$$
\sigma_{c}=C_{p} \sqrt{\frac{F_{t} \times K_{a} \times K_{m}}{b \times d_{p} \times I \times K_{v}}}
$$

Also, AGMA equation will be used in this investigation to verify that the presented contact stress model is accurate and it can be used to predict the behavior of contact stress on the tooth under non-ideal conditions.

The same involute toothed gear model which was used in bending stress analysis section will be used in the contact stress analysis. Single pair of engaged teeth, see Fig. 18, was selected to conduct this study. The model of the gear teeth was meshed using the solid tetrahedral elements with average element size of $1 \mathrm{~mm}$. Fine mesh was used at teeth contact areas as shown in Fig. 19.

Contact element pair has been formulated between the two teeth using rigid-to-flexible and surface-to-surface contact element. Augmented Lagrange method was selected as a procedure to solve contact problem in finite element analysis, defining the contact and target surface has been done as shown in Fig. 20.

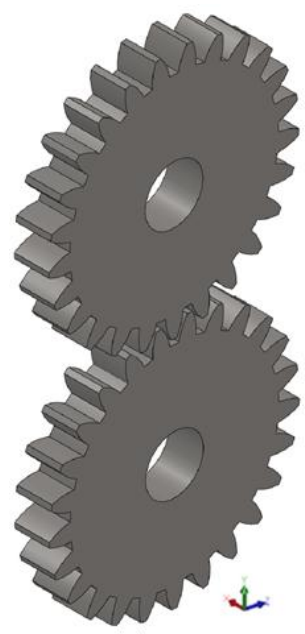

(a)

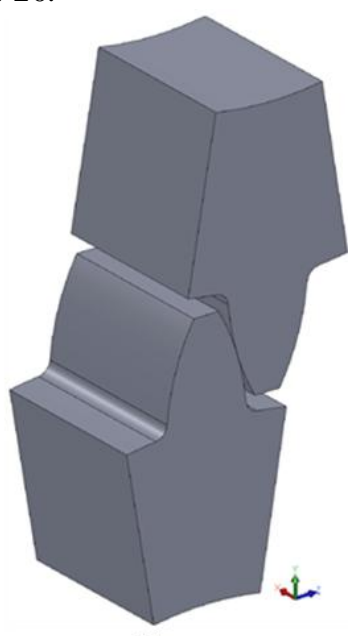

(b)
Fig. 18: (a) Engaged gear model (b) Single pair of engaged tooth model

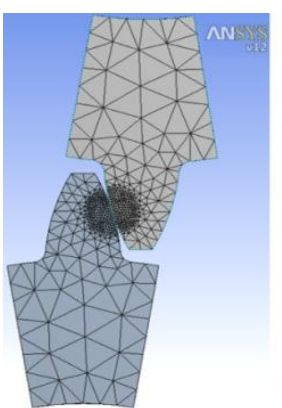

(a)

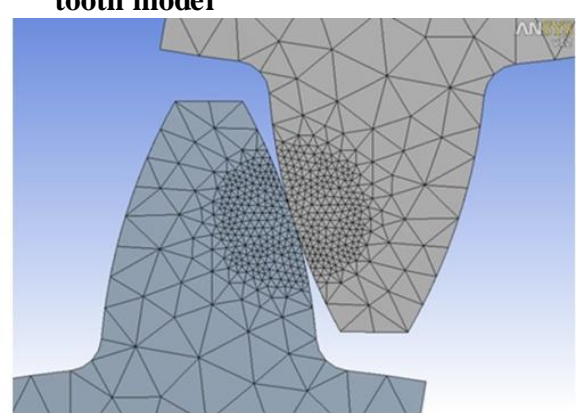

(b)
Fig. 19: (a) Meshing of contact teeth model, (b) Fine mesh near contact areas.
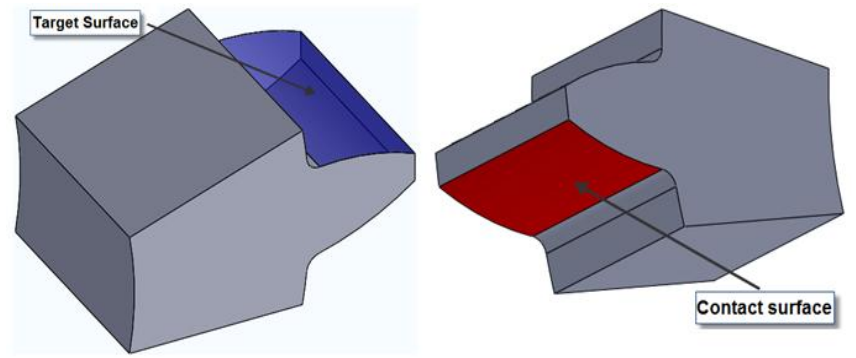

Fig. 20: Contact and target surface of the contact pair

the contact model was fully constrained. The tooth which transmits the load was modelled as a rigid body and it was given s mall rotational displacement. The tooth on mating gear was constrained as fixed support. A normal force of $1.064 \mathrm{KN}$ was applied to the tooth. This normal force accounts for the effects of radial and tangential components. Constrains of the contact model and applied load are shown in Fig. 21.

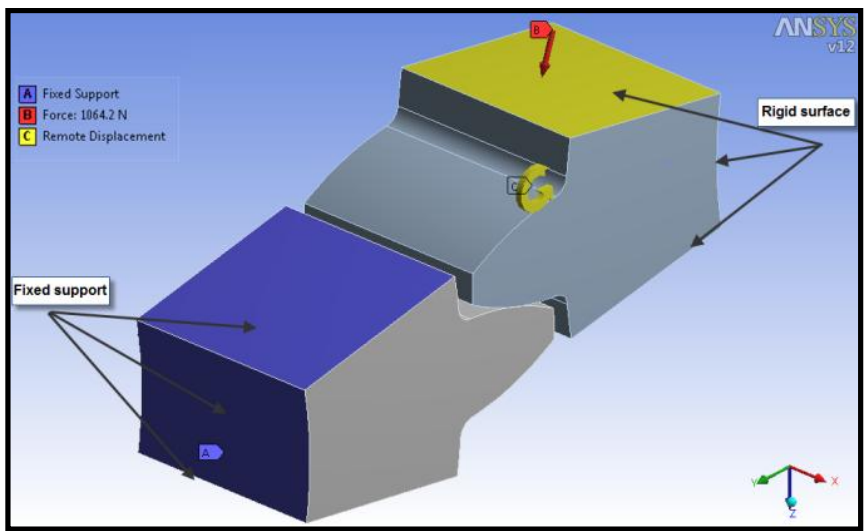

Fig. 21: Constrains and applied load of one pair of engaged gear tooth model

Accordingly, results of contact stress and shear stress in $X Y$-plane are given in Fig. 22 and Fig. 23 respectively.

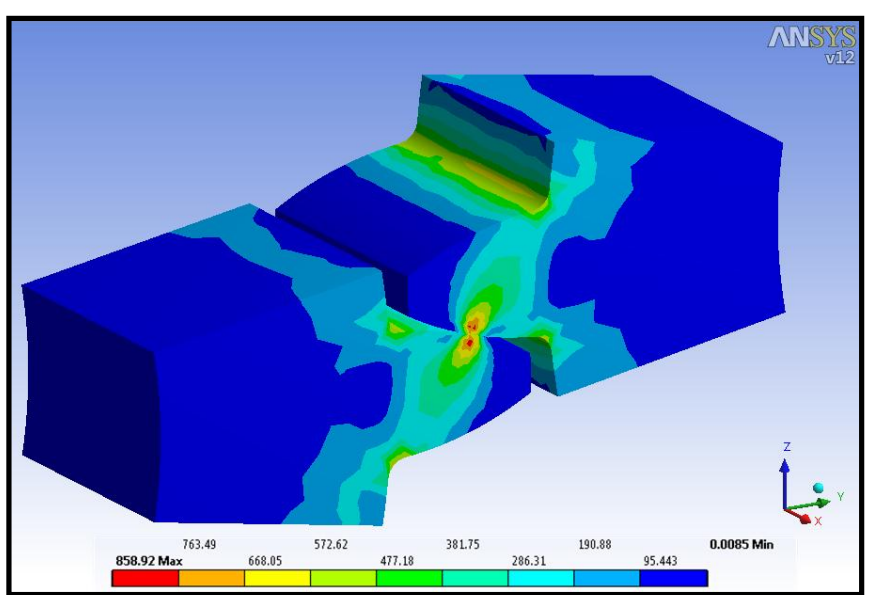

Fig. 22: Equivalent contact stress from ANS YS 


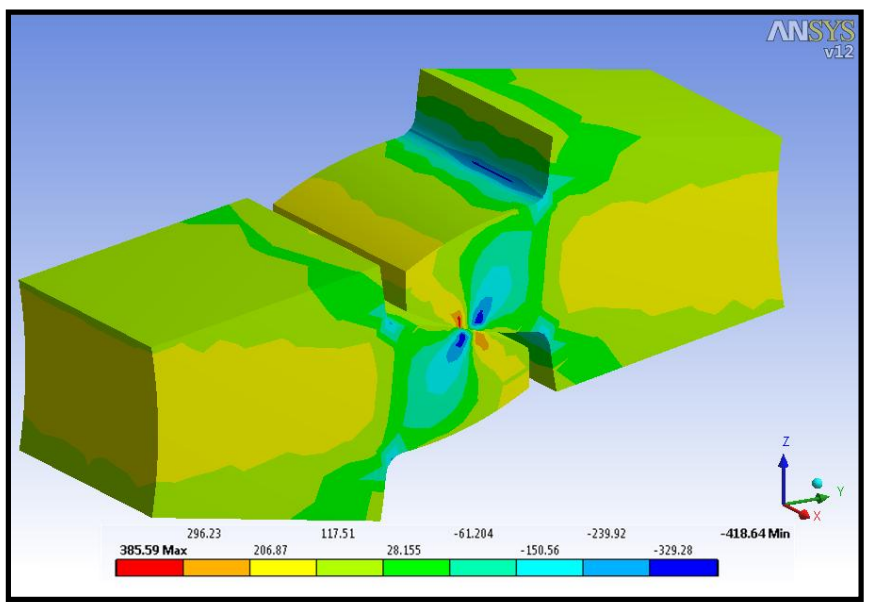

Fig. 23: Equivalent shear stress in XY-plan from ANSYS

Using average values of modification factors (cp, $I, k_{a}$, $\left.k_{m}, k_{v}\right)$ in AGMA equation, then the contact stress $\sigma_{c}$ will be calculated by equation (3) as,

$$
\sigma_{c}=191 \sqrt{\frac{1000 \times 1.25 \times 1.3}{15 \times 100 \times 0.088 \times 0.7}}=800.98 \mathrm{MPa}
$$

By the present finite element analysis, the maximum contact stress was found to be about $859 \mathrm{MPa}$.. This is good agreement between ANSYS model and AGMA equation.

\subsection{Effects of misalignment in contact model}

It has shown that the contact stress model is satisfactorily accurate to calculate contact stress on gear teeth. Therefore, the contact stress model will be used to predict the behavior of the contact stress acting on the gear tooth under the effect of misalignment in various directions as those shown in Fig. 5.

\subsubsection{Gears misalign in the vertical plane}

The constructed contact stress model was used, and some developments on the contact model have been introduced to agree with the requirements of the study. When shafts are misaligned in the vertical plane, a new contact model is developed, as the two teeth in contact have a misalignment angle $\theta_{l}$ in vertical plan as seen in Fig. 24-b.

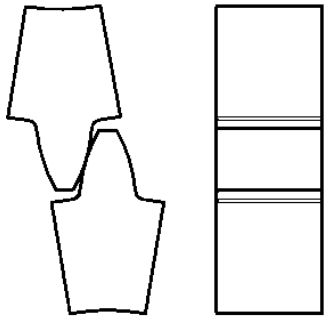

(a)
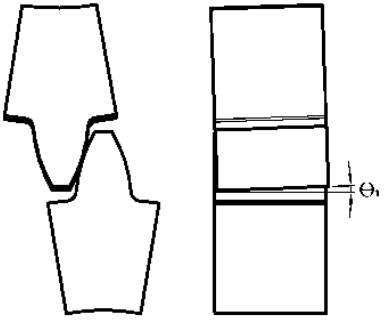

(b)
Fig. 24: Configuration of misalignment in the vertical plane (a) Without misalignment, (b) With misalignment
The misalignment angle $\theta_{l}$ investigated in the vertical plane changes from $0^{\circ}$ to $2^{\circ}$. Also, three different modules $(\mathrm{m}=2,3,4 \mathrm{~mm})$ for the same gear geometry have been used. Same boundary conditions and same applied load has been used as those used in the previous contact model.

Figures 25 and 26 illustrate the effect of the misalignment angle $\theta_{1}$ in the vertical plane on the tooth contact stress $\sigma_{c}$ for different investigated modules. It can be seen that the increasing misalignment angle $\theta_{l}$ in the vertical plane results in increasing the contact stress. The rate of increasing of the contact stress for $\mathrm{m}=2$ is higher than for $\mathrm{m}=3$ and $\mathrm{m}=4$.

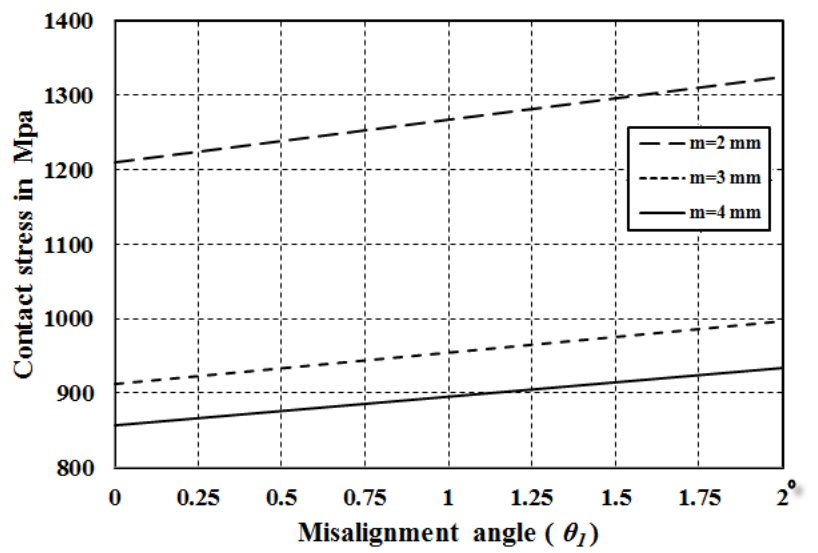

Fig. 25: Contact stress vs. misalignment angle in the vertical plane for different modules

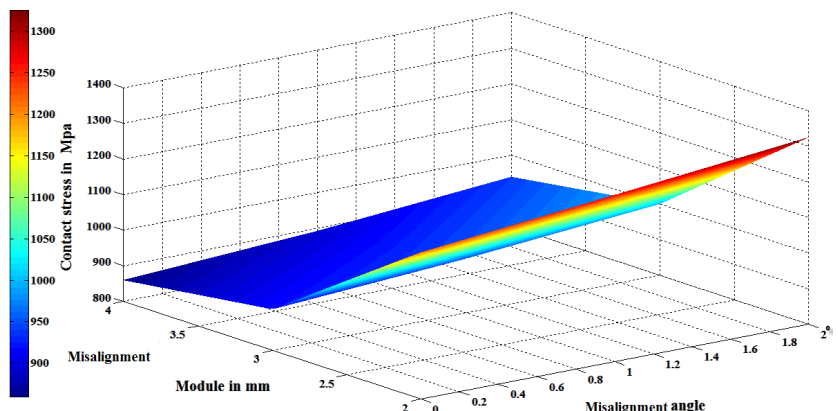

Fig. 26: Contact stress vs. misalignment angle in the vertical plane for different modules in 3D-plot

Figure 27 shows the contact stress distribution over the gear tooth for $\mathrm{m}=4 \mathrm{~mm}$ with and without misalignment of $2^{0}$ in the vertical plane.

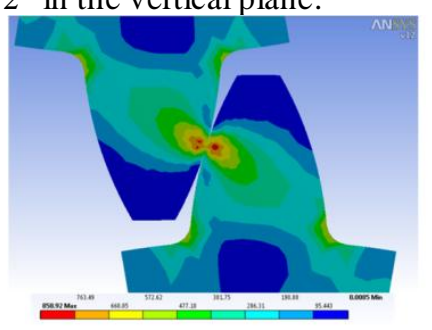

(a)

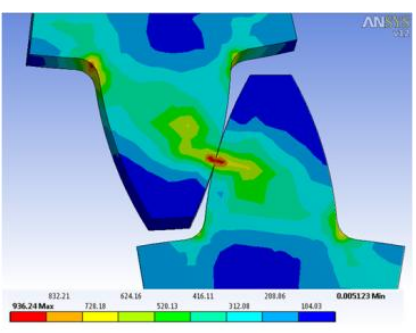

(b)
Fig. 27: Contact stress distribution over the tooth of $4 \mathrm{~mm}$ module (a) without misalignment, (b) with $2^{\circ}$ misalignment in vertical plane 


\subsubsection{Gears misalign in the horizontal plane}

When shafts are misaligned in the horizontal plane, a new contact model is developed, as the two teeth in contact have a misalignment angle $\theta_{2}$ in horizontal plan as shown in Fig. 28.

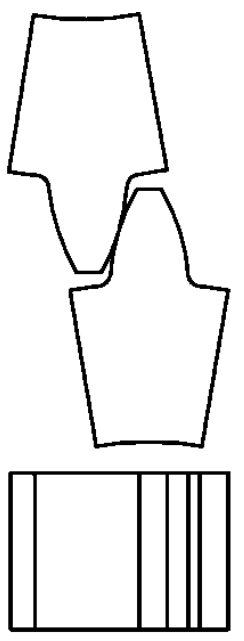

(a)

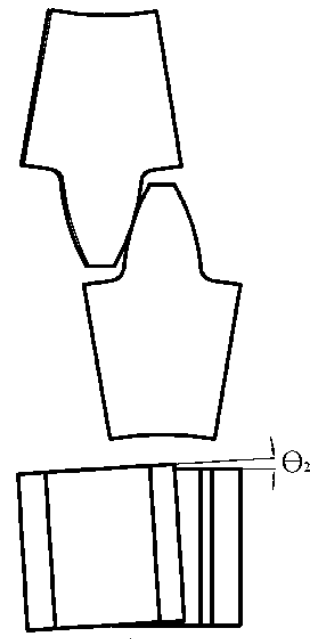

(b)
Fig. 28: Configuration of misalignment in the horizontal plane (a) without misalignment, (b) with misalignment

The misalignment angle $\theta_{2}$ investigated in the horizontal plane changes from $0^{\circ}$ to $2^{\circ}$. Also, three different modules $(\mathrm{m}=2,3,4 \mathrm{~mm})$ for the same gear geometry have been used. Same boundary conditions and same applied load has been used as those used in the contact model.

Figures 29 and 30 illustrate the effect of the misalign ment angle $\theta_{2}$ in the horizontal plane on the tooth contact stress $\sigma_{c}$ for different investigated modules. It can be seen that the increasing in misalignment angle $\theta_{2}$ in the horizontal plane results in increasing the contact stress. Also, the rate of increasing of the contact stress for $m=2$ is higher than for $\mathrm{m}=3$ and $\mathrm{m}=4$.

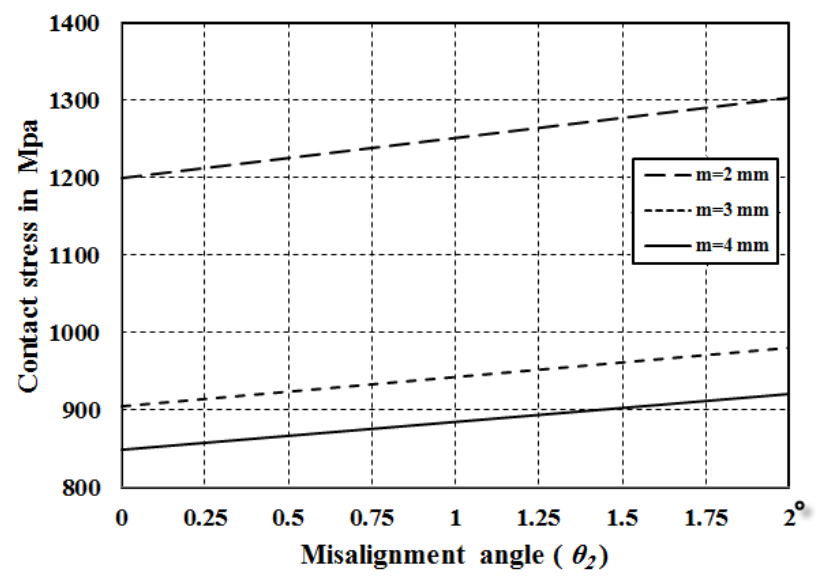

Fig. 29: Contact stress vs. misalignment angle in the horizontal plane for different modules

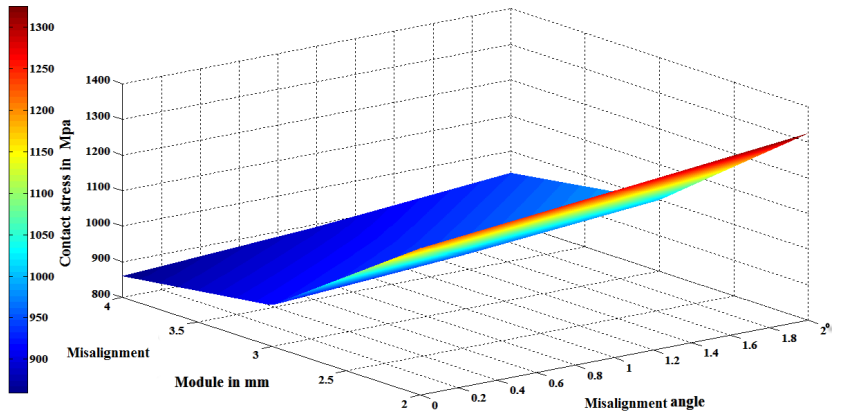

Fig. 30: Contact stress vs. misalignment angle in the horizontal plane for different modules in 3D-plot

Figure 31 shows the contact stress distribution over the gear tooth for $\mathrm{m}=4 \mathrm{~mm}$ with and without misalign ment of $2^{0}$ in the horizontal plane.

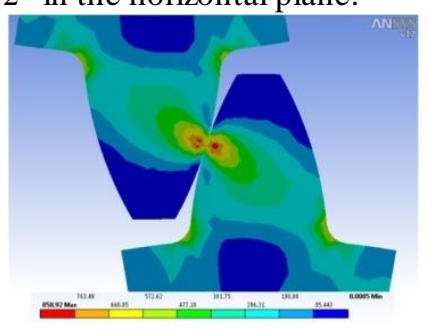

(a)

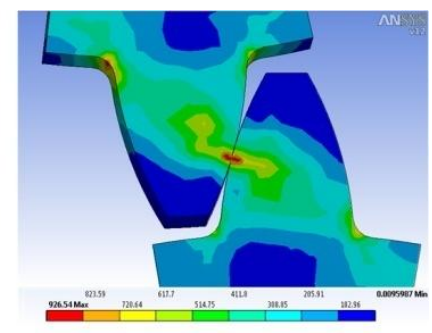

(b)
Fig. 31: stress distribution over the tooth of $4 \mathrm{~mm}$ module (a) without misalignment, (b) with $2^{o}$ misalignment in horizontal plane

\subsubsection{Gears misalign in both vertical and horizontal plane}

When shafts are misaligned in both vertical and horizontal planes, a new contact model is developed to simulate the misalignment angles $\theta_{1}$ in vertical plane and $\theta_{2}$ in horizontal plane as illustrated in Fig. 32.

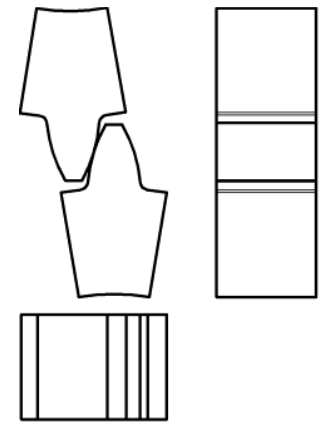

(a)

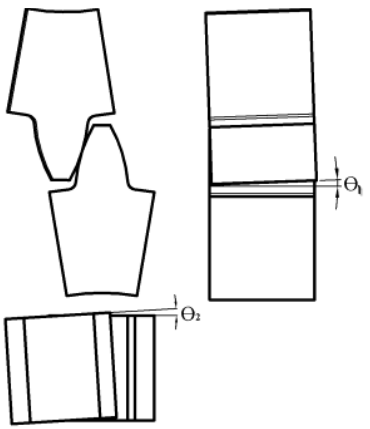

(b)
Fig. 32: Configuration of misalignment in the vertical and horizontal planes (a) without misalignment, (b) with misalignment

The study has been done assuming equal misalignment angles $\theta_{1}$ and $\theta_{2}$ in the vertical and horizontal planes, which are changed equally from $O^{\circ}$ to $2^{\circ}$ in each case. Using three different modules $(\mathrm{m}=2,3,4 \mathrm{~mm})$ for the same gear geometry have been used. Same boundary conditions and same applied load has been used as those used in the contact model. 
Figures 33 and 34 illustrate the effect of the misalign ment angles $\theta_{1}$ and $\theta_{2}$ on the tooth contact stress $\sigma_{c}$ for different investigated modules. It can be seen that the increasing misalignment angles $\theta_{1}$ and $\theta_{2}$ results in increasing the contact stress for all modules. Also, it can be seen that module of $2 \mathrm{~mm}$ has the maximum contact stress.

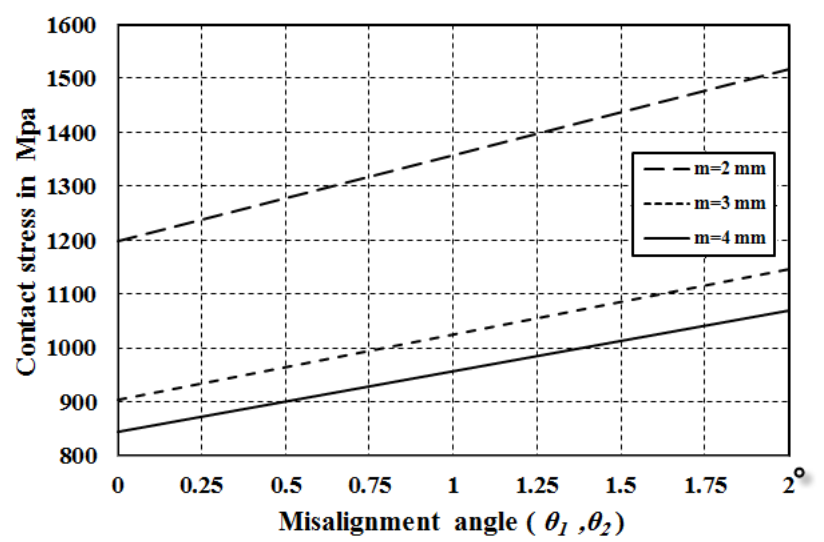

Fig. 33: Contact stress vs. misalignment angle in the vertical and horizontal planes for different modules
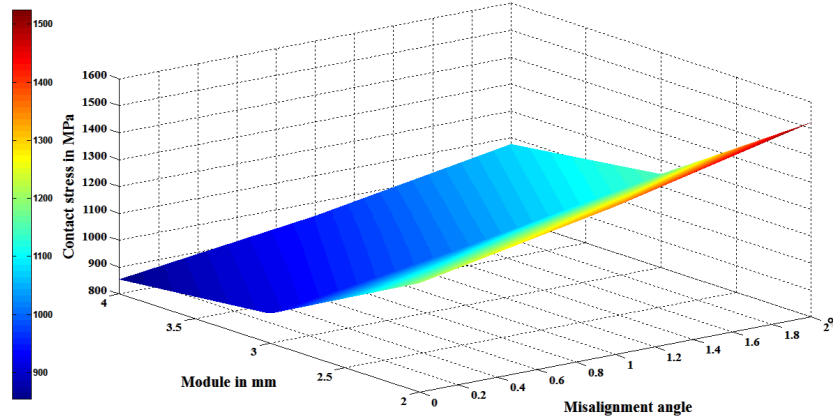

Fig. 34: Contact stress vs. misalignment angle in the vertical and horizontal planes for different modules in 3D-plot

Contact stress distribution over the gear tooth at constant module of $4 \mathrm{~mm}$ is given without misalignment and with misalignment of $2^{0}$ in the vertical and horizontal planes in Fig. 35.

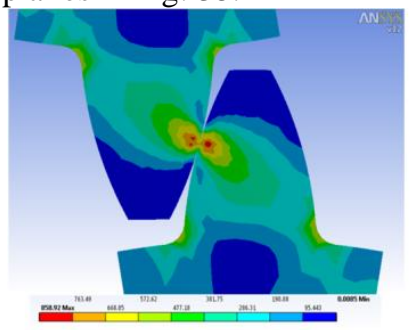

(a)

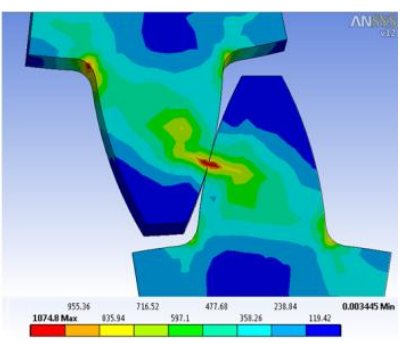

(b)
Fig. 35: Contact stress distribution over the tooth of $4 \mathrm{~mm}$ module (a) without misalignment, (b) with $2^{o}$ misalignment equally in vertical and horizontal planes

\section{CONCULOTION}

Simulation results show that the stresses distribution over the tooth are uniformly distributed when proper alignment is secured, when the axis of gears are parallel. Furthermore, as the shaft misaligned, the values and distribution of equivalent stresses change with changing the misalignment angle. This is due to the stress concentration is increasing, in the contact region and in the root of the tooth, with increasing the misalignment angle. Stress concentration is increased on the side of concentrated load and is decreased on the other side of the gear face.

Furthermore, the probability of fracture the gear increases in the root with increasing the misalignment angle. Moreover, the probability of gear surface pitting increases, as well.

Additionally, the deformation of gear tooth increases with increasing in misalignment angle.

\section{REFERENCES}

1. Vatkar, S., "Design of a Two Stage Ep icyclic Gearbox in Sintered Metal Gears", M. SC. Thesis, Wichita State University, India, 2007.

2. Wei, Z., "Stresses and Deformations in Involute Spur Gears by Finite Element Method", M. Sc. Thesis, University of Saskatchewan, Canada, 2004.

3. Decaires, J.K., "Variation Analysis of Involute Spline Tooth Contact", M. Sc. Thesis, University of Brigham Young, United Kingdom, 2006.

4. Rixin, X., "Finite Element Modeling and Simu lation on the Quenching Effect for Spur Gear Design Optimization", M. Sc. Thesis, University of Akron, USA, 2008.

5. Stoker, K., C., "A Finite Element Approach to Spur Gear Response and Wear Under non-Ideal Loading", M. Sc. Thesis, University of Florida, USA, 2009.

6. Patel, S., "Finite Element Analysis of Stresses in Involute Spur and Helical Gear", M. Sc. Thesis, University of Texas at Arlington, USA, 2010.

7. Gupta, B., Choubey, A., and Varde, G., "Contact Stress Analysis of Spur Gear", International Journal of Engineering Research \& Technology, Volume 1, Issue 4, 2012.

8. Panchal, J., K., "Spur Gear Analysis Using Mathcad", M. Sc. Thesis, University of Texas at Arlington, USA, 2012.

9. Kandil, A., "Machine Design", 2nd Edition, Suze Canal University, Egypt, 2010.

10. Shigley, E.J., Mischke, C.R., and Budynas, R.G., "Mechanical Engineering Design", 7th Edition, Mc Graw Hill, 2004.

11. Norton, R.L., "Machine Design an Integrated Approach", 3rd Edition, Prentace-Hall, USA, 2004.

12. www.efunda.com, "Materials alloys properties", "AISI 1020 alloy".

13. Mackaldener, M., "Tooth Interior Fracture and Robustness of Gears", PhD Thesis, Royal Institute of Technology, Stockholm, Sweden, 2001. 